Medication Use (SEAMS), Brief Medication Questionnaire (BMQ), The Medication Adherence Rating Scale (MARS). Không có thang đo đạt tiêu chuẩn vàng đánh giá tuân thủ thuốc, tuy nhiên thang đo của Morisky có độ tin cậy nhất quán hơn cả [8]. Ở nghiên cứu này do hạn chế về thời gian nghiên cứu cũng như nhân lực y tế, nhóm nghiên cứu của chúng tôi đã sử dụng thang đo của Morisky đo lường tuân thủ điều trị. Ưu điểm của thang đo là xác định được các rào cản của tuân thủ điêuu trị, là thang đo ngắn nhất, dễ cho điểm nhất và phù hợp với nhiêuu nhóm thuốc

Trong bộ câu hỏi tình trạng tuân thủ Morisky, quên uống hoặc tiêm thuốc chiếm tỷ lệ cao (48,5\%). Bên cạnh đó tỷ lệ quên mang thuốc khi đi du lịch chiếm tỷ lệ 31,5\%. Như vậy nhân viên y tế cần giáo dục sức khỏe về tâm quan trọng của điều trị thuốc thường xuyên, đều đặn. Các đối tượng trong nghiên cứu của chúng tôi có tuổi trung bình cao $(73,2 \pm 8,3)$, do vậy bên cạnh việc giáo dục cho bệnh nhân thì giáo dục sức khỏe cho người chăm sóc cũng đóng vai trò quan trọng.

\section{KẾT LUÂ̂N}

Tỷ lệ tuân thủ điều trị kém hoặc không tuân thủ ở bệnh nhân đái tháo đường cao tuổi chiếm $22,8 \%$, trong đó phần lớn do quên thuốc. Như vậy để nâng cao tỷ lệ tuân thủ điều trị, giáo dục sức khỏe cho người bệnh và người chăm sóc đóng vai trò quan trọng.

\section{TÀI LIÊU THAM KHẢO}

1. Whiting, D.R., et al., IDF Diabetes Atlas: Global estimates of the prevalence of diabetes for 2011 and 2030. Diabetes Research and Clinical Practice, 2011. 94(3): p. 311-321.

2. Morrison, A., M.E. Stauffer, and A.S. Kaufman, Defining medication adherence in individual patients. Patient preference and adherence, 2015. 9: p. 893-897.

3. Krass, I., P. Schieback, and T. Dhippayom, Adherence to diabetes medication: a systematic review. Diabet Med, 2015. 32(6): p. 725-37.

4. Lee, W.C., et al., Prevalence and economic consequences of medication adherence in diabetes: a systematic literature review. Manag Care Interface, 2006. 19(7): p. 31-41.

5. Association, A.D.J.D.c., Updates to the Standards of Medical Care in Diabetes-2018. 2018. 41(9): p. 2045.

6. Lewinski, A.A., et al., Addressing Diabetes and Poorly Controlled Hypertension: Pragmatic mHealth Self-Management Intervention. 2019. 21(4): p. e12541.

7. Gholamaliei, B., et al., Medication adherence and its related factors in patients with type II diabetes. 2016. 2(4): p. 3-12

8. Culig, J. and M.J.C.a. Leppée, From Morisky to Hill-bone; self-reports scales for measuring adherence to medication. 2014. 38(1): p. 55-62.

\title{
SỰ THAY ĐỔI VỊ TRÍ RĂNG CỬA VÀ MÔ MỀM TRÊN PHIM SỌ NGHIÊNG TỪ XA CỦA BÊNH NHÂN SAI KHỚP CẮN LOAI II TIỂU LOAI 1 CÓ NHỔ BỐN RĂNG HÀM NHỎ
}

\section{Đỗ Lê Phương Thảo', Võ Thị Thúy Hồng ${ }^{2}$, Nguyễn Thị Thu Phương ${ }^{1}$}

\section{TÓM TẮT}

Mục tiêu: Nhận xét sự thay đổi của vị trí răng cửa và mổ mềm trên phim sọ nghiêng từ xa của bệnh nhân sai khớp cắn loại II tiểu loại 1 có nhổ bốn rắng hàm nhỏ. Đối tượng và phương pháp nghiên cứu: Nghiên cứu mô tả dựa trên đo đạc phim so nghiêng từ xa trước điều trị và sau điều trị của 31 bệnh nhân (21 nữ, 10 nam) sai khớp cắn loại II tiểu loại 1 có nhổ bốn răng hàm nhỏ tại Viện Đào tạo Răng Hàm Mặt và Bênh viên Răng Hàm Măt Trung Ương Hà Nôii đến tháng 6/2021. Kết quả nghiên cứu: Tuổi trung bình 18,65 (11- 34). Góc SNA, góc SNB thay đổi không có ý

\footnotetext{
IViên Đào Tạo Răng Hàm Măt, Đại hơc Y Hà Nộ 2Bềnh viên Răng Hàm Măt Trung Ương Hà Nôi Chịu trách nhiệm chính: Đỗ Lê Phương Thảo Email: Dolephuongthaorhm@gmail.com Ngày nhận bài: 6.7.2021 Ngày phản biên khoa hoc: 31.8.2021 Ngày duyệt bài: 8.9.2021
}

nghĩa thống kê. Răng cửa trên được dựng thẳng truc nhiều $10,19 \pm 9,07^{\circ}$ so với nền sọ, $9,84 \pm 8,60^{\circ}$ so với măt phằng hàm trên và $10,13 \pm 7,40^{\circ}$ với so với NA với $\mathrm{p}<0,001$. Trục răng cửa dưới so với mặt phẳng hàm dưới đã được dựng thẳng 4,53 $\pm 7,31^{0}$ và đước ngả lưỡi so với mặt phẳng NB $6,60 \pm 5,25^{0}$ rất có ý nghĩa thống kê. Góc trục liên răng cửa tăng 15,94 \pm $12,82^{\circ}$. Độ nhô môi trên và môi dưới so với đường $\mathrm{E}$ và so với ŚnPog' đều giảm rất nhiều sau điều tri với $p$ $<0,001$. Góc mũi môi, đô dày môi trên, môi dưới và phần mềm cằm có thay đổi nhưng không có ý nghĩa thống kê $(p>0,05)$. Kết luận: Các chỉ số về vị trí răng cửa và mô mềm trên phim so nghiêng từ xa của bênh nhân sai khớp cắn loai II tiểu loai 1 có nhổ bốn răng hàm nhỏ cho thấy: răng cửa trển và răng cửa dưới đều được dựng thẳng trục và dịch chuyển ra sau. Góc liên trục răng cửa tăng. Độ nhô của hai môi so với đường thẩm mỹ $\mathrm{E}$ và SnPog' giảm. Góc mũi môi, chiều dày môi, độ dày mô mềm vùng cằm không thay đổi sau điều tri. Tư khóa: răng cửa, mô mềm, khớp cắn loai II tiểu loại 1, phim sọ nghiêng, răng hàm nhỏ, nhổ răng. 


\section{SUMMARY}

INCISOR POSITION AND SOFT TISSUE CHANGES IN CLASS II DIVISION 1 MALOCCLUSIONS WITH FOUR PREMOLARS EXTRACTION BY EVALUATE PRE-TREATMENT AND POST- TREATMENT LATERAL CEPHALOMETRIC RADIOGRAPHY Objectives: To evaluate the effects of premolars extraction on incisor position and soft tissue profile in patients with Class II, division 1 malocclusion. Materials and method: Descriptive study by evaluate pre- treatment and post- treatment cephalometric radiography of 31 patients ( 21 females, 10 males) diagnosed with class II division 1 malocclusion with four premolars extraction in School of Odonto- Stomatology and National Hospital Of Odonto- Stomatology to June 2021 were recruited. Results: The average of age was 18,65 (range in 11 to 34). The SNA and SNB angles changed no significantly during treatment. The inclination of upper incisor in relations with cranial base, palatal plane and NA decreased by $10,19 \pm 9,07^{\circ}, 9,84 \pm 8,60^{\circ}$ and $10,13 \pm 7,40^{\circ}$ respectively. The inclination of lower incisor in relations with mandible plane and NB decreased by $4,53 \pm 7,31^{\circ}$ and $6,60 \pm 5,25^{\circ}$ respectively. Interincisal angle increased by $15,94 \pm$ $12,82^{\circ}$. We observed a highly significant increase in the distance between the upper and lower lips and the esthetic line and SnPog' line. No significant differences were apparent in the nasolabial angle, the lips thickness and chin thickness. Conclusions: Between the start and the end of treatment, class II division 1 malocclusions with four premolars extraction experienced more retruded upper and lower incisors. The wider interincisal angle showed a decrease of bimaxillary protrusion. The distance between the upper and lower lips and the esthetic line and SnPog' line decreased dramatically showed positive effects on the facial profile. No significant differences in the nasolabial angle, lip thickness and chin thickness during treatment.

Key words: incisor, soft tissue, class II division 1 malocclusion, cephalometric, premolar, extract

\section{I. ĐĂT VẤN ĐỀ}

Sai khớp cắn loai II tiểu loại 1 ảnh hưởng nhiều đến thẩm mỹ khuôn mă̆t nhất là khi nhìn nghiêng. Hiện nay, việc gia tăng nhận thức và sự quan tâm về thẩm mỹ khuôn mặt của con người góp phần làm tăng nhu cầu điểu trị chỉnh nha, đăc biêt ở những bênh nhân có lệch lac khớp cắn. Hầu hết các nhà chỉnh nha đều thừa nhận rằng sự thành công của điều trị chỉnh nha là đạt đước hiệu quả thẩm mỹ trên mô mềm, cải thiện thẩm mỹ khuôn măt. Một trong những muc tiểu điều trị chỉnh nha cho những bệnh nhân có khớp cắn loại II tiểu loại 1 là cải thiện thẩm mỹ mặt nghiêng, nhằm mục đích có được tương quan môi, răng, măt nghiêng hài hòa. Do đó, đánh giá được sự thay đổi mô mềm sau điều trị là việc vô cùng quan trọng. Khi phân tích mô mềm, chúng ta không thể không chú ý đến hệ thống nâng đõ̃ bên dưới, mặc dù khi đánh giá thẩm mỹ khuôn mặt chủ yếu là đánh giá mô mềm. Mô mềm nhìn nghiêng có phản ánh được hê thống xương-răng theo chiều trước sau hay không? Mức độ dịch chuyển của răng cửa có tác động lên vị trí của môi hay không? ở Việt Nam, chúng tôi thấy nghiên cứu về vấn đề này trên bệnh nhân có lệch lạc khớp cắn loại II tiểu loại 1 còn ít. Vì vậy, chúng tôi thực hiện nghiên cứu này với mục tiêu: Nhân xét sứ thay đổi của vị trí răng cửa và mô mềm trên phim so nghiêng từ xa của bênh nhân sai khớp cắn loại II tiểu loại 1 có nhổ bốn răng hàm nhỏ; nhằm bước đầu đưa ra môt số nhận định về các tác động của điều trị chỉnh nha có nhổ răng trên nhóm bệnh nhân người Việt.

\section{II. ĐỐI TƯỢNG VÀ PHƯƠNG PHÁP NGHIÊN CỨU}

a. Đối tượng nghiên cứu. Gồm 31 bệnh nhân đến khám và điều trị tại các cơ sở khám chữa bệnh của Viện Đào Tạo Răng Hàm Mặt và Bệnh Viện Răng Hàm Mặt Trung Ương Hà Nội tới tháng 6/2021, thoả mãn các điều kiện sau:

Tiêu chuấn lựa chọn: Bệnh nhân là người Việt Nam; có hàm răng vĩnh viễn, được chẩn đoán sai khớp cắn Angle II tiểu loại 1, được điều trị chỉnh nha bằng mắc cài cố định hai hàm có chỉ định nhổ 4 răng hàm nhỏ với: tương quan răng hàm lớn vĩnh viễn thứ nhất và tương quan răng nanh loại II; độ cắn chìa $>3 \mathrm{~mm}$; bệnh nhân có phim sọ nghiểng từ xa trước và sau điều trị, mẫu hàm trền và hàm dưới, hồ sơ điều trị.

Tiêu chuân đánh giá phim: Chất lượng phim chụp tốt (đánh giá về độ sáng, tối và độ phân giải); thấy rõ được đầy đủ phần xương và phần mềm sọ mặt; hai lỗ tai và đường cành ngang xương hàm dưới trùng nhau.

Tiêu chuẩn loại trừ: Bị dị tật bẩm sinh vùng hàm mặt; có tiền sử chấn thương hàm mặt; thiếu răng vĩnh viễn vì bất kỳ lý do nào (không kể răng hàm lớn thứ ba); bệnh nhân có chỉ định phẫu thuật chỉnh hình xương; các bệnh nhân không đủ các tiêu chuẩn lựa chọn trên.

b. Thiết kế nghiên cứu: Nghiên cứu mô tả theo dõi doc

Chọn mẫu chủ đích 31 bệnh nhân đáp ứng đầy đủ tiêu chuẩn lựa chọn và tiêu chuẩn loại trừ, đồng ý tham gia nghiên cứu cho đến khi đủ cõ̃ mẫu nghiên cứu.

c. Thu thập số liệu. Tiến hành vẽ nét trên phim sọ nghiêng từ xa trước điều trị (thời điểm T1) và sau điều trị (thời điểm T2): Vẽ các nét, xác định các điểm mốc ở mô mềm và mô cứng; kẻ các đường giải phẫu; các phim có hai nét vẽ 
thì vẽ hai đường sau đó lấy đường giữa; độ phóng đại trên phim được xử lý trong quá trình xử lý số liệu để đảm bảo các giá trị đo trên phim sọ nghiêng cuối cùng đều giống nhau theo tỉ lệ 1:1. Số liệu sau khi đo đạc ghi vào bệnh án nghiên cứu.

d. Xử lý số liệu. Số liệu được nhập liệu và phân tích bằng phần mềm SPSS 20.0. Các biến định lượng được kiểm định bằng phép kiểm định $T$ và Wilcoxon. Các biến định tính được kiểm định Khi bình phương hoặc Fisher. Giá trị $\mathrm{p}<0,05$ được coi là có ý nghĩa thống kê.

e. Đạo đức nghiên cứu. Nghiên cứu được

Bảng 3.1. Sự thay đổi vị trí răng cửa sau điều trị

\begin{tabular}{|c|c|c|c|c|}
\hline \multirow[t]{2}{*}{ (2) } & Trước điêu trị (T1) & Sau điều trị (T2) & Thay_đối (T2-1) & \multirow{2}{*}{$\mathbf{p}$} \\
\hline & $X \pm S D$ & $\mathrm{X} \pm \mathrm{SD}$ & $X \pm S D$ & \\
\hline SNA $\left({ }^{0}\right)$ & $83,74 \pm 3,40$ & $83,60 \pm 4,45$ & $-0,15 \pm 2,26$ & $0,426 * *$ \\
\hline $\operatorname{SNB}\left({ }^{0}\right)$ & $77,13 \pm 3,71$ & $77,27 \pm 3,57$ & $0,15 \pm 1,56$ & $0,607^{*}$ \\
\hline U1-SN $\left({ }^{0}\right)$ & $110,36 \pm 8,21$ & $100,16 \pm 7,99$ & $-10,19 \pm 9,07$ & $0,000^{*}$ \\
\hline U1-PP $\left(0^{0}\right)$ & $120,57 \pm 8,14$ & $110,73 \pm 8,23$ & $-9,84 \pm 8,60$ & $0,000 *$ \\
\hline U1-NA $\left({ }^{0}\right)$ & $27,92 \pm 7,15$ & $17,79 \pm 7,90$ & $-10,13 \pm 7,40$ & $0,000 *$ \\
\hline U1-NA (mm) & $6,95 \pm 2,60$ & $1,62 \pm 2,65$ & $-5,34 \pm 3,05$ & $0,000 *$ \\
\hline $\operatorname{L1} 1-\mathrm{MP}\left({ }^{0}\right)$ & $102,10 \pm 5,62$ & $97,57 \pm 7,27$ & $-4,53 \pm 7,31$ & $0,002 * *$ \\
\hline $\operatorname{L1-NB}\left({ }^{0}\right)$ & $37,39 \pm 4,02$ & $30,79 \pm 5,15$ & $-6,60 \pm 5,25$ & $0,000 *$ \\
\hline L1-NB (mm) & $10,64 \pm 2,28$ & $7,35 \pm 2,22$ & $-3,29 \pm 2,49$ & $0,000^{*}$ \\
\hline U1-L1 $\left({ }^{0}\right)$ & $109,79 \pm 8,08$ & $124,73 \pm 10,17$ & $15,94 \pm 12,82$ & $0,000 * *$ \\
\hline
\end{tabular}

(Dấu "-": Chỉ số giảm sau điều trị; *: T-test; **: Wilcoxon-test)

- Góc SNA, góc SNB thay đổi không có ý nghĩa thống kê sau điều trị với $p>0,05$.

- Răng cửa trên được dựng thẳng trục nhiều $10,19 \pm 9,07^{\circ}$ so với nền sọ, $9,84 \pm 8,60^{\circ}$ so với mặt phẳng hàm trên và $10,13 \pm 7,40^{\circ}$ với so với NA có ý nghĩa thống kê với $p<0,001$.

- Rìa cắn răng cửa trên di xa theo mặt phẳng tham chiếu NA 5,34 $\pm 3,05 \mathrm{~mm}$ với $p<0,001$. sự chấp thuận của Trường Đại học Y Hà Nội, Bệnh viện Răng Hàm Mặt Trung Ương Hà Nội và Trung tầm Kỹ thuật cao khám chữa bệnh Viện đào tạo Răng Hàm Mặt.

\section{KẾT QUẢ NGHIÊN CỨU}

Đặc điểm chung của đối tượng nghiên cứu: Nghiên cứu có 31 bệnh nhân, trong đó có 21 nữ $(67,7 \%)$ và 10 nam $(32,3 \%)$, sự khác biệt về giới có ý nghĩa thống kê với $p<0,05$. Tuổi trung bình là 18,65 , lớn nhất 34 tuổi và nhỏ nhất 11 tuổi, trong đó tỉ lệ bệnh nhân dưới 18 tuổi chiếm $51,6 \%$.
- Trục răng cửa dưới so với mặt phẳng hàm dưới đã được dựng thẳng trục trung bình 4,53 \pm $7,31^{0}$ có ý nghĩa thống kê với $p<0,05$ và được ngả lưỡi so với mă̆t phẳng $\mathrm{NB} 6,60 \pm 5,25^{\circ}$ rất có ý nghĩa thống kề với $p<0,001$.

- Góc trục liên răng cửa tăng $15,94 \pm 12,82^{\circ}$ chứng tỏ độ vẩu của răng đã được giảm.

Bảng 3.2. Sự thay đổi mô mè̀m sau điều trị

\begin{tabular}{|c|c|c|c|c|}
\hline & Trước điêuu trị (T1) & Sau đîêu trị (T2) & Thay đối (T2-1) & \\
\hline & $X \pm S D$ & $X \pm S D$ & $X \pm S D$ & p \\
\hline ULth (mm) & $13,88 \pm 1,99$ & $14,09 \pm 1,97$ & $0,21 \pm 0,81$ & $0,163^{*}$ \\
\hline LLth (mm) & $16,11 \pm 2,24$ & $16,21 \pm 2,24$ & $0,09 \pm 0,59$ & $0,380 *$ \\
\hline Pog-Pog'(mm) & $12,63 \pm 2,27$ & $12,14 \pm 1,84$ & $-0,49 \pm 1,79$ & $0,135^{*}$ \\
\hline Góc mũi môi $\left({ }^{0}\right)$ & $94,18 \pm 11,78$ & $96,58 \pm 11,94$ & $2,40 \pm 6,98$ & $0,065^{*}$ \\
\hline 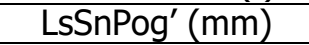 & $8,79 \pm 1,84$ & $7,22 \pm 1,65$ & $-1,58 \pm 1,64$ & $0,000 *$ \\
\hline 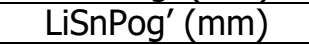 & $8,96 \pm 2,73$ & $6,24 \pm 2,16$ & $-2,68 \pm 2,12$ & $0,000 *$ \\
\hline $\begin{array}{l}\text { Khoảng cách Ls- } \\
\text { Đường } \mathrm{E}(\mathrm{mm})\end{array}$ & $3,01 \pm 2,25$ & 2,13 & 48 & $0,000 *$ \\
\hline $\begin{array}{l}\text { Khoảng cách từ Li- } \\
\text { Đường } \mathrm{E}(\mathrm{mm})\end{array}$ & $5,61 \pm 2,61$ & $3,46 \pm 2,66$ & $-2,15 \pm 2,27$ & $0,000^{*}$ \\
\hline
\end{tabular}

(Dấu "-": Chỉ số giảm sau điều trị; *: T-test; **: Wilcoxon-test)

- Đô̂ nhô môi trên và môi dưới so với đường $\mathrm{E}$ và so với $S n P o g$ ' đều thay đổi rất nhiều, giảm có ý nghĩa thống kê sau điều trị với $p<0,001$, cho thấy vẩu môi đã được cải thiện, mặt nghiêng của 
cằm có thay đổi nhưng không có ý nghĩa thống kê $(p>0,05)$.

\section{BÀN LUÂ̂N}

Góc SNA và góc SNB đều không thay đổi bởi điều trị. Nghiên cứu của Suwannee trên nhóm bệnh nhân người Thái cũng cho kết quả tương tự và kết luận rằng sự sai lệch về tương quan xương gần như không thay đổi sau điều trị chỉnh nha. ${ }^{1}$ Điều này có thể giải thích là: về mặt sinh cơ học, do dịch chuyển răng bằng nắn chỉnh răng là kết quả của tạo hình lại xương ổ răng dưới tác động của lực nên xương nền hàm thay đổi rất ít vì vậy nếu bệnh nhân có vẩu cả xương và răng thì phải kết hợp với phẫu thuật để chỉnh xương còn nắn chỉnh răng chỉ làm uổn xương ổ răng về phía vòm miệng hay phía lưỡi.

Sau điều trị, vị trí của răng cửa có sự thay đổi nhiều. Độ nghiêng của trục răng cửa rất quan trọng đối với thẩm mỹ và hài hòa của khuôn mặt. Răng cửa trên và răng cửa dưới không những được dựng thẳng trục mà còn được kéo lui đáng kể làm giảm độ vẩu. Răng cửa trên và dưới được dựng thẳng trục nhiều hơn so với kết quả của Suwannee trên người Thái và Bishara trên người Mỹ da trắng, nhưng thấp hơn người Nhật trong nghiên cứu của Hayashida. ${ }^{1-3}$ Lý do cho sự khác biệt này là mục tiêu giảm độ vẩu không giống nhau giữa các các cá thể, cho nên răng cửa trong thực tế có thể dịch chuyển nhiều hơn so với kế hoạch đặt ra nhưng do để có mặt hài hòa thì chỉ cần một lượng nhất định dịch chuyển. Do đó, sự khác nhau về mức độ dịch chuyển giữa các nghiên cứu chỉ có ý nghĩa so sánh thống kê và không có ý nghĩa về mặt đánh giá mức độ thành công hay thất bại của phương pháp điều trị trên lâm sàng.

Kết quả nghiên cứu của chúng tôi cho thấy độ nhô môi trên và môi dưới sau điều trị đã giảm đáng kể so với đường thẩm mỹ $\mathrm{E}: 1,72 \pm 1,48$ $\mathrm{mm}$ và $2,15 \pm 2,27 \mathrm{~mm}$, so với đường SnPog': $1,58 \pm 1,64 \mathrm{~mm}$ và $2,68 \pm 2,12 \mathrm{~mm}$, cho thấy hai môi được giảm vẩu đáng kể, nét mặt nghiêng của bệnh nhân hài hòa hơn.

Góc mũi mồi tăng không đáng kể sau điều trị với $p>0,05$. Kết quả của chúng tôi tương đồng với nghiên cứu của Weyrich trên người Đức khi góc mũi môi trong nghiên cứu này chỉ tăng $1^{0}$ sau điều trị và không có ý nghĩa thống kê. ${ }^{4}$ Theo Fitzgerald, sự thay đổi của mô mềm vùng mũi môi diễn ra độc lập với sự thay đổi của mô cứng bên dưới nó. ${ }^{5}$ Ramos cũ̃ng ủng hộ quan điểm này khi nhận thấy không có mối tương quan chặt chẽ giữa sự thay đổi góc mũi môi với mức độ lui sau của rìa cắn răng cửa. ${ }^{6}$ Bên cạnh đó, góc mũi môi còn bị ảnh hưởng bởi độ dốc của trụ mũi và độ dày môi. Độ dốc của trụ mũi giảm theo tuổi và môi dày có thể là những yếu tố làm góc mũi môi không thay đổi nhiều sau điều trị.

Chiều dày môi trên và chiều dày môi dưới sau điều trị thay đổi không có ý nghĩa thống kê. Trong khi chụp phim sọ nghiêng, bệnh nhân phải hoàn toàn thư giãn các cơ mặt để loại bỏ khả năng căng cơ. Nếu khi chụp phim sọ nghiêng các bệnh nhân cố khép kín môi hoặc chưa thực sự làm cơ thư giãn hết gây ra căng cơ tăng thì có thể là nguồn dẫn tới sai số.

Độ dày mô mềm vùng cằm thay đổi rất ít sau điều trị, tương tự nghiên cứu của Hayashida: chỉ có sự tăng rất nhẹ $0,59 \mathrm{~mm}$ ở vùng này. ${ }^{3}$ Theo Burstone, mô mềm quanh miệng có thể tự thay đổi và các yếu tố khác ngoài dịch chuyển của răng và mô cứng cũng có thể gây ra đáp ứng trên mô mềm tùy vào đặc điểm của từng cá thể. ${ }^{7}$ Suhatcha khi phân tích các yếu tố ảnh hưởng đến mô mềm trên bệnh nhân khớp cắn loại II tiểu loại 1 có nhổ răng đã kết luận: ở vùng cằm, chỉ có sự dịch chuyển ra trước và xuống dưới của điểm Pog mô mềm và điểm Me mô mềm là có ý nghĩa thống kê. ${ }^{8}$ Hơn nữa, các chuyển động này bị ảnh hưởng bởi nhiều yếu tố thuộc cá nhân như giới, góc mặt phẳng hàm dưới, và không có mối tương quan giữa sự dịch chuyển theo chiêu ngang của điểm Pog mô mềm với điều trị. ${ }^{8}$ Chính vì vậy, không có sự suy diễn tuyệt đối chính xác số liệu về sự thay đổi về mô cứng và sự thay đổi về mô mềm mà phải đánh giá tổng thể sự thay đổi của từng cá nhân dựa theo các đặc điểm giải phẫu riêng biệt.

\section{KẾT LUÂ̂N}

Sự thay đổi sau điều trị của bệnh nhân sai khớp cắn loại II tiểu loại 1 có nhổ bốn răng hàm nhỏ thông qua việc đánh giá trên phim sọ nghiêng từ xa cho thấy: Các răng cửa trên và răng cửa dưới đều được dựng thẳng trục và dịch chuyển ra sau, góc liên trục răng cửa tăng, chứng tỏ vẩu răng được cải thiện. Độ nhô của hai môi so với đường thẩm mỹ $\mathrm{E}$ và $\mathrm{SnPog}$ giảm, cho thấy bệnh nhân có mặt nghiêng hài hòa hơn. Góc mũi môi, chiều dày môi, độ dày mô mềm vùng cằm không thay đổi bởi điều trị.

\section{TÀI LIÊU THAM KHẢO}

1. Luppanapornlarp $\mathbf{S}$, Johnston Jr LE. The effects of premolar-extraction: a long-term comparison of outcomes in "clear-cut" extraction and nonextraction Class II patients. The Angle Orthodontist. 1993;63(4):257-272. 
2. Bishara SE. Mandibular changes in persons with untreated and treated Class II division 1 malocclusion. Am J Orthod Dentofacial Orthop. $1998 ; 113(6): 661-673$. 5406(98)70227-6

3. Hayashida H, Ioi H, Nakata S, Takahashi I, Counts AL. Effects of retraction of anterior teeth and initial soft tissue variables on lip changes in Japanese adults. The European Journal of Orthodontics. 2011;33(4):419-426.

4. Weyrich $\mathbf{C}$, Lisson $\mathbf{J A}$. The effect of premolar extractions on incisor position and soft tissue profile in patients with Class II, Division 1 malocclusion. J Orofac Orthop. 2009;70(2):128138. doi:10.1007/s00056-009-0813-2

5. Fitzgerald JP, Nanda RS, Currier GF. An evaluation of the nasolabial angle and the relative inclinations of the nose and upper lip. American Journal of Orthodontics and Dentofacial Orthopedics. 1992;102(4):328-334.

6. Ramos AL, Sakima MT, Pinto A dos $S$, Bowman SJ. Upper lip changes correlated to maxillary incisor retraction--a metallic implant study. Angle Orthod. 2005;75(4):499-505. doi:10.1043/0003-

3219(2005)75[499:ULCCTM]2.0.CO;2

7. Burstone $\mathbf{C J}$. Lip posture and its significance in treatment planning. Am J Orthod. 1967;53(4):262284. doi:10.1016/0002-9416(67)90022-x

8. Maetevorakul S, Viteporn S. Factors influencing soft tissue profile changes following orthodontic treatment in patients with Class II Division 1 malocclusion. Prog Orthod. 2016;17:13. doi:10.1186/s40510-016-0125-1

\title{
THỰC HÀNH VỀ DINH DƯỡNG Ở HỌC SINH Có VẤN ĐỀ VỀ RĂNG MIÊNG TẠI TRƯỜ'NG TIỂU HỌC THI TRẤN VŨ THƯ, TỈNH THÁI BÌNH NĂM 2019
}

\author{
Ngô Văn Mạnh¹, Lê Đức Cường1, Phạm Thị Quý
}

\section{TÓM TẮT 18}

Một nghiên cứu cắt ngang thực hiện trên 324 hoc sinh lớp 4 và lớp 5 của Trường tiểu hoc thi trấn Vũ Thư tỉnh Thái Bình nhằm xác định tỷ lệ học sinh có vấn đề răng miêng và đánh giá thực hành về dinh dưỡng ở học sinh mắc bệnh lý răng miệng. Kết quả nghiên cứu cho thấy: Trong số 324 học sinh được điêu tra có 115 học sinh có vấn đề về răng miệng, tỷ lệ học sinh có vấn đề về răng miêng không ăn 3 bữa thường xuyên ở trẻ nam cao hơn trẻ nữ (lần lượt là $59,3 \%$ và $50,0 \%$ ), sự khác biệt không có ý nghĩa thống kê với $p>0,05$. Tỷ lệ bỏ ăn sáng ở 2 giới đều cao với $85,7 \%$. Tỷ lể học sinh nữ có thói quen ăn đồ ngot và uống nước có ga cao hơn nam giới. Tuy nhiên tỷ lệ học sinh nam có thói quen uống đồ tự pha tại tiệm cao hớn trẻ nữ.

Từ khóa: Thực hành, học sinh, dinh dưỡng, bệnh răng miệng.

\section{SUMMARY \\ NUTRITIONAL PRACTICE IN PUPILS WITH DENTAL PROBLEMS AT PRIMARY SCHOOL IN VU THU TOWN, THAI BINH PROVINCE IN 2019}

A cross-sectional study was conducted on 324 4th and 5th grade pupils of Primary School in Vu Thu Town, Thai Binh province to determine the proportion of pupils with dental problems and to assess nutrition practice among these pupils. Results of the study show that: Among 324 pupils were interviewed, there were 115 pupils with dental problems. The percentage

${ }^{1}$ Trường Đại học Y Dược Thái Bình.

²Bênh viên Đa khoa Vũ Thư, Thái Bình

Chịu trách nhiệm chính: Ngô Văn Mạnh

Email: manhsdh@gmail.com

Ngày nhận bài: 6.7.2021

Ngày phản biên khoa hoc: 27.8.2021

Ngày duyệt bài: 8.9.2021 of pupils with dental problems who do not eat 3 regular meals in boys is higher than that in girls (with $59.3 \%$ and $50.0 \%$, respectively), the difference is not statistically significant $(p>0.05)$. The rate of skipping breakfast in both gender are high with $85.7 \%$. The percentage of girls who eating sweet foods and drinking carbonated water frequently is higher than that of boys. However, the percentage of boys who have a habit of drinking homemade drinks at the shop is higher than that of girls.

Keywords: Practice, students, nutrition, dental disease.

\section{I. ĐĂT VẤN ĐỀ}

Dinh dưỡng là một thành phần thiết yếu trong sự tăng trưởng, phát triển và duy trì cuộc sống lành manh của con người [1]. Riêng đối với sự phát triển hệ răng, chế độ dinh dưỡng tốt sẽ cung cấp những dưỡng chất cần thiết cho quá trình cấu tạo nướu và răng của trẻ. Dinh dưỡng và bệnh răng miêng có mối tương quan với nhau [2], khi dinh dưỡng tốt, chăm sóc răng miệng tốt thì sẽ hạn chế các bệnh răng miệng nhưng thiếu dinh dưỡng (thể thiếu cân và thấp còi) có thể khiến môt người bị sâu răng. Thành phần dinh dưỡng của một món ăn, cách tiêu thụ món ăn đó cũng có thể ngăn ngừa hoặc gây ra bệnh cho hàm răng. Ngược laị, tình trang tốt xấu của răng- miêng cũng có ảnh hưởng vào sự dinh dưỡng của cơ thể [3]. Ở nước ta, cùng với sự thay đổi và phát triển về điều kiện kinh tế xã hội trong những năm gần đây là sự gia tăng việc sử dung đường sữa, bánh keo, nước uống có ga nhiều hơn trong khi đó người dân đặc biệt là lứa tuổi học sinh chưa nhận thức đầy đủ về tác hại 